April 1st.-The same fluid was continued, and a purgative enema administered, which acted well; pulse moderate; great aversion to everything.

2nd.-He appeared much the same; pulse ranging from 80 to 100; ptyalism from the first has been distressingly constant; he complains of much pain in the course of the cesophagus, and in the cardiac extremity of the stomach.

$3 \mathrm{rd}$ - - Had most severe pain during the night, apparently from swallowing a little dissolved calf's-foot jelly, and hiccup came on in the afternoon; this distressed him much, and he was very feeble; a disagreeable odour was perceptible in the eructations.

4th. - Had a good night, until five o'clock, when the pain became very severe; the odour from the stomach was highly offensive to himself and the attendants. As the pain was now becoming intolerable, small doses of muriate of morphine were given from time to time, and the bowels were kept in action by repeated enemas.

5th.-I was called up to him in the night, in consequence of arterial hæmorrhage from either the csophagus or stomach; the coagula which formed in the stomach caused him to vomit; pain very great, and the hiccup more frequent and distressing. A dose of morphine tranquillized him during the day, and he appeared better, but hæmorrhage recurred in the afternoon.

6th.-Every way better, but troubled with a constant discharge of glairy fluid from the throat. Allowed to take some arrow-root.

7th.-Less fotor and hiccup; evacuations from the bowels very black, and highly offensive. He feels better, and in less pain.

8th.-Motions still very black and fotid, but he feels in every way better.

From this time onward he complained of much pain in the stomach, and sinapisms were occasionally applied. The discharge of glairy fluid continued for some time in large quantities. The fluid first drawn from the stomach was analyzed by my son, Dr. D. S. Price and Mr. Nicholson, at the Royal College of Chemistry, and I subjoin their report:-

"A careful quantitative examination of the liquid sent us has proved the poison in question to be hydrochloric acid. Metals were particularly songht for, but with negative results. On the bottle being uncolked, a strong spirituous odour was perceptible. In order to verify the presence of alcohol, the highly acid fluid was neutralized with pure carbonate of soda, and subjected to distillation in a water-bath. The distillate was tested for alcohol, by adding to it a few drops of concentrated solution of bichromate of potassa and hydrochloric acid; instant reduction of the chromic acid ensued on heating, the odour of aldehyde being at the same time powerfully developed. The contents of the retort were remored into a dish, evaporated to dryness, and ignited, in order to destroy organic matter, the residue was treated with water, filtered, and the hydrochloric acid determined in the usual manner with nitrate of silver. The anoun of chloride of silver obtained corresponds very nearly to about three drachms and a half of muriatic acid, sp. gr. $1 \cdot 17$, the common fuming commercial acid.

$$
\text { (Signed) David S. Price, Ph. D. }
$$

E. Chambers Nicholson."

The success with which the stomach-pump was used in this case, proves, contrary to some opinions, that it may and ought to be used at an early stage in cases of poisoning with mineral acids.

Margate, July, 1850 .

ON A

GUNSHOT WOUND OF THE FEMORAL ARTERY, PRODUCING A FALSE ANEURISM. OPERATION, AND RECOVERY.

By HENRY WATERWORTH, Esq., M.R.C.S. \&c., Newport, Isle of Wight.

ON Wednesday, April 25th, 1849, I was sent for to Mr. D. Waged 21 , who had received a wound in the thigh, from the accidental explosion of an air-gun. The ball had eniered about the middle of the thigh, exactly over the course of the femoral artery; profuse hæmorrhage ensued, but was soon arrested, by the patient himself tying a handkerchief around the limb. Fearing the dangerous proximity of the wound to the artery, I determined to take no steps to explore it until I had procured assistance, which was promptly rendered by $\mathrm{my}$ friend, $\mathrm{Mr}$. Tuttiett. After slightly dilating the wound, and carefully probing it, we found it to extend downwards and inwards, and then upwards, and we hoped the femoral artery had escaped injury. Water dressing and a bandage were applied, and perfect quiet was enjoined. On visiting him the next morning, I found he had passed a good night, and there had been no further hæmorrhage; but on my second visit, in the evening, his friends were in great alarm, recurrence of the hæmorrhage having taken place, though this had been again stopped before I saw him. I now observed a pulsation over the artery, and a vibratory murmur, which was evident throughout the thigh. I remained during the night with him, and the next day had another consultation with $\mathrm{Mr}$. Tuttiett, who agreed with me as to the nature of the case, and the almost inevitable necessity for an operation. This being communicated to his friends, we had the patient carefully removed to Newport, his residence being six miles in the country. In the meantime, we thought it right to try the effect of a compress and bandage from the toes to the groin, for a day or two. He continued in the same state, and on Sunday, the 29 th, a consultation was held with my friend Staff-Surgeon Dowse, of Parkhurst Barracks, by the wish of the patient's friends, as they had heard " he had been in a great many wars." He also coincided with our opinion, and we fixed on the next day for the operation. The question now arose, whether we should cut into the sac at the seat of injury, and tie the vessel above and below, or merely tie the artery in the upper part of the thigh-a much easier operation. After mature deliberation, we decided on the former, being more especially led to this opinion from reading Mr. Guthrie's lectures on this subject in THE IANCET. The operation was rendered rather tedious, from $m y$ bein embarrassed by considerable venous hæmorrhage, from the application of the toumiquet, the use of which was rendered necessary by a violent gush of arterial blood taling place immediately on open. ing the sac, notwithstanding very firm pressure was made on the artery above. The ligatures were placed round the artery without difficulty; the wound by which the ball had entered being very perceptible. The patient was kept under the influence of chloroform until towards the close of the operation. The whereabouts of the ball could not be detected. The $\operatorname{limb}$ was care. fully enveloped in filannel, but no alteration in temperature was perceptible at any time. The last ligature came away on the fourteenth day, and the patient recovered without an unfavourable symptom, excepting a small abscess on the dorsum of the foot, which required opening. He returned home in the beginning of June, and has felt no inconvenience from the ball, the presence of which can be felt in the region of the wound.

Newport, 1850 .

\section{ON COTTON WADDING AS AN APPLICATION TO BED-SORES AND VARICOSE ULCERS.}

Bx ROBERT JONES, M.R.C.S.L., Conway, North Wales.

I WAs summoned to visit a young girl, aged 16, residing some distance in the country, who had been laid up with typhus fever for the previous month. I had seen her for the first time about a fortnight before. It is probable that I might not have been called to this case, had not the nurse observed (to use her expression) that the patient was getting as black as a coal under her. Haring examined the poor girl, I found that matters were almost as bad as the nurse bad stated; the integuments covering the nates were quite black, and the posterior spine and crest of the ilium almost laid bare; the discharge therefrom was very profuse and offensive. She was very weak, and dreadfully emaciated. Her tongue being clear, and bowels open, I desired them at once to give her some wine and bark, at the sanve time allowing her some nourishing broth and beef tea. It occurred to me that $I$ would apply some cotton wadding to the part, with the intenticn of giving her a soft cushion to lie on, as well as to absorb the abundant discharge; she complained and cried much from her back, but after the application was made she appeared much relieved. I made my second visit in three days after, having desired the nurse not to remore the cotton, except in places where it became moist from the discharge. On examination, I found things going on farourably, the part covering spine and crest of ilium were granulat ng very nicely, the slough covering them had already partially separated, and the parts beneath were looking very well. I did not visit her again until to-day (March 4th), and I find that she is convalescent. I have also treated successfully a few cases of varicose ulcers of the lower extremities, by the application of the cotton wadding; the manner of applying it is simply to cover the ulcer, and dressing the patient every second or third day, a roller being applied after the cotton. At the same time I enjoin pexfect quietness, and keeping the limb in the horizontal position. I have found three weeks or a month a sufficient time to get them well. North Wales, 1850. 